\title{
Effects of subphonetic and syllable structure variation on word recognition
}

\author{
JENNIFER AYDELOTT UTMAN, SHEILA E. BLUMSTEIN, and MARTHA W. BURTON \\ Brown University, Providence, Rhode Island
}

\begin{abstract}
This study explored whether natural acoustic variations as exemplified by either subphonetic changes or syllable structure changes affect word recognition processes. Subphonetic variations were realized by differences in the voice-onset time (VOT) value of initial voiceless stop consonants, and syllable structure variations were realized by vowel deletion in initial unstressed syllables in multisyllable words. An auditory identity priming paradigm was used to determine whether the amount of facilitation obtained to a target stimulus in a lexical decision task was affected by the presence of these acoustic variations in a prime stimulus. Results revealed different patterns for the two types of variability as a function of lexical status. In the case of subphonetic variations, shortening of VOT resulted in reduced facilitation for words but not for nonwords, whereas in the case of syllable structure variation, vowel deletion in an unstressed syllable resulted in reduced facilitation for nonwords and increased facilitation for words. These findings indicate that subphonetic variability interferes with word recognition, whereas syllable structure variability does not, and that this effect is independent of the magnitude of the acoustic difference between a citation form and its variant. Furthermore, the results suggest that the lexical status of the target item plays a crucial role in the processing of both types of variability. Results are considered in relation to current models of word recognition.
\end{abstract}

In normal speech production, the acoustic realization of a particular sound or sequence of sounds may vary for an individual speaker due to a number of factors. Some acoustic variability occurs in the natural implementation of speech. For instance, the implementation of voicing in stop consonants may vary along a range of parameter values of voice-onset time (VOT) corresponding to the voiced and voiceless phonetic category (e.g., Kessinger \& Blumstein, 1997; Miller, Green, \& Reeves, 1986). Other variability arises as a result of effects of phonetic context. For instance, the same phonetic segment may be realized differently depending on the phonetic context. For example, $/ \mathrm{p} /$ is aspirated in syllable-initial position, but not following an /s / (e.g., Klatt, 1975). Still another factor is speaker style. Both casual speech and speaking rate can affect the phonetic manifestation of an utterance. For example, a word-final stop consonant may be deleted when it occurs between fricatives that share its place of articulation, as in list some $\rightarrow$ /lis sam/ (Klatt, 1979, 1986; cf. Frauenfelder \& Lahiri, 1989). Similarly, unstressed vowels in pre-

This work was supported by NIH Grant DC00142 to Brown University. The authors thank Robert Remez, Doùg Whalen, and Paul Luce for their comments on an earlier version of this manuscript. Many thanks to Talya Salz for her assistance in running subjects and analyzing some of the data used in the experiment. M. W. Burton is now at the Department of Neurology, University of Maryland School of Medicine. Correspondence should be addressed to J. A. Utman, who is now at the Department of Experimental Psychology, University of Oxford, South Parks Road, Oxford OX1 3UD, England (e-mail: jennifer.utman@ psy.ox.ac.uk). stressed position in English may be deleted in fast or casual speech, as in police $\rightarrow$ [plis] (Dalby, 1985).

In all of the above examples, acoustic variability results in multiple acoustic exemplars or variants of the same lexical representation. The presence of such variability in the speech signal is a crucial problem for auditory language processing, particularly in the case of word recognition and lexical access, in which the language processing system must map a set of disparate acoustic patterns onto a single word-level representation. Thus, different tokens of a sound that fall within a phonetic category must be recognized as variants of the same segment, and, in some cases, different sequences of phonetic segments must be recognized as variants of the same word. All of these variants are graded in the sense that they occur along an acoustic continuum, and they occur as a function of a number of factors, including articulatory variability, speaking style, or tempo (cf. Dalby, 1985).

However, certain types of variability differ in that the range of values associated with a particular phonetic target may have differential effects on the syllabic structure of a lexical item. For example, in the case of the production of voiceless stop consonants in initial position, there is a range of VOT values that correspond to the voiceless phonetic category. Despite this range of values, the syllable structure of the stimulus remains the same. In contrast, there are certain conditions under which a two-syllable utterance may be produced as one syllable. For instance, in the example described above, the word police is produced in citation form as two syllables [pəlis] and as one syllable [plis] in rapid or casual speech. Thus, the syllable 
structure of the word varies as a function of speaking style or tempo, and the full range of variation extends from two syllables at one end of the continuum to one syllable at the other end.

In this study, our goal was to explore the mapping process from sound structure to lexical form and, in particular, to investigate how these different manifestations of phonetic variation are ultimately mapped onto the same lexical representation. Most particularly, we were interested in determining whether these types of phonetic variation are treated by the word recognition system in a similar fashion, despite the fact that the phonetic variation maintains the syllable structure in one case and changes it in the other.

Recent research has suggested that phonetic variations that are within category and that maintain the syllable structure of the utterance are perceived by listeners and can affect lexical access. In particular, Andruski, Blumstein, and Burton (1994) demonstrated a significant reduction in semantic facilitation in a lexical decision priming task for target words when the initial VOT of the related prime word was reduced by two thirds relative to prime words containing intact values for initial VOT (e.g., $c_{-2} 2 / 3$ VOT $a t-d o g$ vs. $c_{\text {intact }} a t-d o g$ ). This effect emerged at interstimulus intervals (ISIs) of $50 \mathrm{msec}$ but disappeared at ISIs of $250 \mathrm{msec}$. On the basis of these results, Andruski et al. concluded that "the representation which is first abstracted from the speech waveform incorporates information contained in the acoustic fine structure, including subphonetic variations; that this low-level acoustic information affects lexical access; and that activation levels in the lexicon are graded" (p. 182). These findings also indicate that these effects are brief and appear to diminish over the course of time.

Similar short-lived reductions in semantic facilitation have since been observed for a number of temporal and spectral acoustic cues, including vowel duration in intrinsically short vowels, as well as voicing in the closure interval of word-final voiced stops (Utman, 1997, 1998b; Utman, Blumstein, \& Sullivan, 1998). Furthermore, the results of these studies have suggested a relationship between the relative "goodness" of an acoustic exemplar and the amount of lexical activation that exemplar produces. Specifically, better exemplars of the intended lexical representation appear to produce more lexical activation, and therefore more semantic priming, than do poorer exemplars (Utman, 1997, 1998b; Utman et al., 1998). Thus, the effect of acoustic variability on lexical access appears to depend on whether the variation produces a better or a poorer exemplar of the target word.

In contrast to the results of the studies reviewed above, several researchers have argued that, rather than posing an obstacle to word recognition, certain types of variability can in fact be useful to the language processing system by providing cues that aid in the segmentation of the speech stream (Church, 1987; Frauenfelder \& Lahiri, 1989; Frazier, 1987). For example, the presence of aspiration on a voiceless stop consonant in English can signal the onset of a syllable or word and might serve to trigger a new lexical search. Recent research suggests that listeners do exploit variability that affects the phonological status of sound segments in the identification of words. Lahiri and Marslen-Wilson (1991) have shown that the same acoustic information is treated differently depending on its linguistic status. Specifically, Lahiri and MarslenWilson demonstrated that vowel nasalization is used differently by speakers of English and by speakers of Bengali. In English, nasalized vowels are not phonemic, and, thus, vowel nasalization can be used as a cue to the presence of a following nasal consonant. In contrast, in Bengali, nasalized vowels are phonemic. Thus, vowel nasalization cannot be used as a cue to the phonetic status of the following segment. Lahiri and Marslen-Wilson's results showed that English listeners use the nasality in a vowel to anticipate the presence of a following nasal consonant, whereas Bengali listeners wait until later in the speech stream to identify a nasal consonant. In a more recent study, Gaskell and Marslen-Wilson (1996) showed no effect of phonological variation stemming from place of articulation assimilation processes, so long as the variation was licensed by the phonetic context. In this case, there was as much priming for [wIkId] as for the phonological variant [wrkrb], which appeared in the context of a following initial bilabial stop as in prank. In contrast, [wikıb] failed to show priming when it appeared in a context where the final [d] could not be recovered from assimilation processes, as in [wıkıb] preceding game. These results indicate that the way in which listeners exploit acoustic information is influenced by the phonological/ phonetic rules of their language.

Some studies have suggested that the effects of subphonetic variation differ depending on the lexical status of the target item. For example, Streeter and Nigro (1979) manipulated word and nonword targets in a lexical decision task by removing the $\mathrm{VC}$ transition in word-medial CVC sequences or by substituting the $\mathrm{VC}$ transition with a transition that conflicted with the preceding CV transition. The results showed that subcategorical phonetic mismatches significantly slowed lexical decision times for altered words relative to unaltered words. In contrast, decision times for nonwords were unaffected by similar manipulations. Thus, Streeter and Nigro concluded that the slower reaction times (RTs) occurred not during initial processing but during lexical lookup.

Whalen (1991) also found that subphonetic withincategory phonetic mismatches slowed lexical decision latencies. He manipulated the noise portion of the fricatives [s] and [J], juxtaposing this noise with incompatible preceding acoustic information (e.g., the fricative noise of mess paired with the word-onset portion of mesh, and vice versa). However, unlike Streeter and Nigro (1979), Whalen found slower lexical decision latencies for both words and nonwords when the stimuli were acoustically altered. As a consequence, he concluded that phonetic mismatches are resolved before lexical access.

Whether acoustic manipulations affect words and nonwords similarly or differently has important implications for models of word recognition and lexical access. Ac- 
cordingly, the interaction of lexical status with the effects of such manipulations was the focus of a recent study by Marslen-Wilson and Warren (1994). Using a similar methodology to Streeter and Nigro (1979), MarslenWilson and Warren systematically varied the lexical status of both the initial CV transition and the final VC portion of each stimulus and examined response latencies in a lexical decision task and in phonetic identification of the final consonant. When conflicting acoustic cues were present, RTs to words increased significantly whether the initial $\mathrm{CV}$ transitions were compatible with a different word or with a nonword, whereas RTs to nonwords were slowed only when the initial CV transitions were compatible with a word. Thus, within-category phonetic mismatches had a different consequence depending on their lexical status. On the basis of their results, MarslenWilson and Warren suggested that nonwords are perceived via the lexicon by analogy to words, and the lexical status effects emerged because nonwords are novel sequences that, in an attractor network, take longer to settle into a stable state. Because of the longer time required to reach a final stable state, subtle time differences in the processing of acoustic variants are lost. Interestingly, both Whalen (1991) and Marslen-Wilson and Warren (1994) argued that the loss of subphonetic differences for nonwords emerged because nonwords take longer to process, although Whalen argues that these effects are prelexical, and Marslen-Wilson and Warren argue that they are a result of processing by analogy to the lexicon.

Another possible account of the interaction of lexical status and subphonetic acoustic differences may be schematized in terms of a graded activation approach to word recognition and lexical access, similar to that described in previous studies (Andruski et al., 1994; Utman, 1997, 1998b; Utman et al., 1998). The different patterns of results obtained for word and nonword targets may arise because, in the case of words, the incoming acoustic information is mapped onto an existing lexical representation. Thus, for words, the acoustic input constitutes one of many possible exemplars of the same lexical entry. Because lexical representations are graded, the amount of activation produced by an acoustic input is dependent on whether the input is a good or a poor exemplar of the target item. Different behavioral effects are therefore obtained for better or poorer acoustic exemplars of word targets in the RT studies described above. In contrast, for nonwords, the incoming acoustic information is a novel form that does not correspond to an existing lexical entry and thus is not sufficient to activate a particular lexical representation beyond its threshold level. Thus, subphonetic acoustic variations are not treated as different exemplars of the same target. Because there is no corresponding graded lexical representation, no difference emerges in RTs to subphonetic acoustic variants.

All of the studies discussed above have explored acoustic variations that maintain the syllable structure of the stimulus. It is not known whether acoustic manipulations that result in changes in syllable structure will have similar effects on word recognition processes. Although there may appear to be categorical differences between acoustic manipulations that maintain syllable structure and those that do not, both are manifested acoustically in a graded or a continuous form as a consequence of continuous variation in articulatory processes (Browman \& Goldstein, 1990). Thus, both subphonetic and syllable structure variations produce a continuum of acoustic variants that may represent better or poorer exemplars of the intended lexical item. This suggests that acoustic variations that alter the syllable structure of a lexical item may have similar effects on lexical activation to variations that are subphonetic in nature. Specifically, variants that are better acoustic exemplars of the target may produce more lexical activation, and therefore faster RTs in a lexical decision paradigm, than variants that are poorer acoustic exemplars. Interestingly, some syllable structure variants reflect a contrast between formal and informal speaking styles, such as the police $\rightarrow$ [plis] example described above. It is not obvious in these cases which variant represents the better exemplar of the target lexical item. Although the fully realized variant represents the citation form of the lexical entry, it is also possible that the reduced form is more frequently encountered and therefore more strongly associated with the underlying lexical representation.

In summary, the results of previous studies indicate that acoustic variation influences word recognition and lexical access, such that better acoustic exemplars produce more activation of word targets than do poorer exemplars. However, a number of questions remain to be addressed. In particular, there is still disagreement as to the role of lexical status in the processing of acoustic variation. In addition, the effects of acoustic variations that produce a change in syllable structure on word recognition processes have not yet been examined.

To explore these issues, we used an auditory identity priming paradigm. Recent research indicates that subjects show faster RTs to lexical decision targets that are acoustically identical to preceding primes than to targets that differ from primes in initial position (at onset) by one or more phonetic features (Burton, 1989; Marslen-Wilson, Moss, \& van Halen, 1996; Slowiaczek \& Pisoni, 1986). The identity priming task is particularly well suited to the issues under consideration, since it allows for the exploration of form-based manipulations on word recognition, without the demands of a recall task and without concern for the strength of semantic relationships required by lexical decision semantic priming tasks. Furthermore, this task allows for a comparison of priming effects for word and nonword targets.

In the present experiment, we directly compared the effects of subphonetic and syllable structure variations on identity priming. Thus, it was important to construct the stimulus set carefully for each type of variation so that the stimuli in the different variation conditions were as similar to each other as possible. By definition, it is impossible to match the phonetic environments and the particular acoustic manipulations for subphonetic variations that, at the extremes of their ranges of variation, either maintain 
syllable structure or result in changes in syllable structure. Nonetheless, having said this, we attempted, to the extent possible, to match the initial consonant of the acoustically manipulated stimulus (voiceless stop consonant) and the type of acoustic manipulation (deletion of acoustic information).

To explore subphonetic variations that maintain syllable structure (called subphonetic variation), we investigated variations in VOT in initial voiceless stop consonants (e.g., peace $\rightarrow$ [pis]). This acoustic manipulation differs from those used by Streeter and Nigro (1979), Whalen (1991), and Marslen-Wilson and Warren (1994), in which the acoustic manipulations involved subcategorical mismatches, where incompatible acoustic attributes are juxtaposed. While such manipulations provide a means for exploring the effects of subphonetic differences on word recognition processes, they are not variations that occur in natural speech. The manipulation of VOT may help to address whether word recognition processes may be similarly affected by acoustic differences resulting from natural variations occurring in speech.

To explore acoustic manipulations that result in changes in syllable structure (called syllable structure variation), we investigated vowel deletion in initial unstressed $\mathrm{CV}$ syllables in multisyllabic words beginning with voiceless stop consonants (e.g., police $\rightarrow$ [plis]). The VOT manipulation reflects a change in within-category structure of the voiceless initial segment and occurs as a result of either articulatory variation occurring at the same speaking rate (cf. Kessinger \& Blumstein, 1997) or speaking rate changes (although changes in speaking rate affect not only VOT but also the following vowel duration; Kessinger \& Blumstein, 1997). The vowel-deletion manipulation, in contrast, reflects a change in the syllable structure of the stimulus and occurs typically in rapid speech when the speaker is talking in an informal register (Dalby, 1985). As noted above, for both subphonetic and syllable structure variations, acoustic information is deleted, and the acoustically manipulated prime stimulus begins with the same initial consonant (voiceless stop consonant [p] or $[\mathrm{k}]$ ). Both word and nonword stimuli were used and were matched for acoustic and phonetic structure.

Several possible patterns of results might emerge. One possibility is that word recognition processes treat all types of acoustic variability similarly. In that case, for both types of variability, RTs to an auditorily presented word target preceded by a variant prime should be slower than RTs to a target preceded by an acoustically identical prime. However, there should be no difference in the magnitude of priming for nonword targets preceded by acoustically identical and acoustically manipulated primes (or the magnitude of the effect should be smaller than that found for words; cf. Whalen, 1991).

On the other hand, the acoustic manipulations for subphonetic and syllable structure variants may have different effects on the goodness of the stimuli. In the case of subphonetic variants (VOT manipulation), the acoustically manipulated stimulus is no longer as good an exemplar of the phonetic category and is closer in acoustic space to the contrasting voiced phonetic category (Andruski et al., 1994; Utman, 1998a). In contrast, in the case of syllable variation (vowel deletion), the acoustically manipulated exemplar is an alternate exemplar or variant, which is not necessarily a poorer exemplar of the target lexical item. Thus, the acoustic manipulations resulting in syllable structure differences may have no effect on word recognition, since these variants may equally activate the lexical candidate. If this is the case, there should be no difference in RTs to two-syllable word targets preceded by a variant with reduced syllable structure and word targets preceded by an acoustically identical stimulus. The results for nonwords may also be different from the word stimuli and from the results for the VOT manipulations. Because the vowel manipulations change the syllable structure of the prime stimuli and hence increase the acoustic distance between prime and target, priming effects for nonwords may be greatly reduced or fail to emerge for these variants.

\section{METHOD}

\section{Stimuli}

To investigate the effects of both subphonetic and syllable structure variability on priming, a set of stimulus words and nonwords was constructed that manipulated VOT in word-initial stop consonants in CVC words and vowel deletion in initial unstressed position in multisyllabic words. The experiment consisted of three priming conditions for each type of variation: identity, in which the prime was acoustically identical to the target; variant, in which the prime was a phonetic variant of the target; and unrelated, in which the prime was a real word that was phonologically/phonetically and semantically unrelated to the target. A similar set of nonword stimuli was also created for each type of variant in order to determine the extent to which the obtained effects reflect word recognition processes or prelexical processes related to low-level acoustic matching.

There were a total of $48 \mathrm{CVC}$ word and nonword targets that were used to explore subphonetic variation (see Appendix A). Target words consisted of $12 / \mathrm{p} /$-initial (e.g., peace) and $12 / \mathrm{k} /$-initial (e.g., keep) nouns, verbs, or adjectives. Nonword targets were created by changing the final phoneme of the word targets by up to two distinctive features (e.g., peace $\rightarrow$ [pif]).

Similarly, a total of 48 multisyllabic word and nonword targets were used to explore syllable structure variation (see Appendix A). Target words included $12 / \mathrm{p} /$-initial (e.g., police) and $12 / \mathrm{k} /$-initial (e.g., collide) nouns, verbs, or adjectives with unstressed first syllables and stressed second syllables beginning with a [+sonorant] consonant. Like the CVC nonwords, multisyllabic nonword targets were created by changing the final phoneme of the target words by up to two distinctive features (e.g., police $\rightarrow$ [polif]).

A set of unrelated prime words and nonwords was assembled for both CVC and multisyllabic targets, consisting of phonologically/ phonetically and semantically unrelated nouns, verbs, or adjectives and their nonword counterparts, created in the manner described above. The unrelated prime words were matched for frequency of occurrence with the lists of targets, such that, for both the CVC and the multisyllabic targets, the unrelated primes had the same number of high-frequency $(>500)$, medium-frequency $(50-500)$, and low-frequency $(<50)$ words as the target sets (Francis \& Kučera, 1982). All multisyllabic unrelated primes had unstressed first syllables and stressed second syllables. Examples of prime-target pairs in all conditions are shown in Table 1.

Because the prime-target pairs for both the word and the nonword stimulus sets appeared only as members of word-word or nonword-nonword pairs, a set of distractor items was constructed 
Table 1

Examples of Word and Nonword Primes and Targets Across Test Conditions

\begin{tabular}{|c|c|c|c|c|c|}
\hline \multirow[b]{2}{*}{ Variability Type } & \multirow[b]{2}{*}{ Lexical Status } & \multirow[b]{2}{*}{ Item } & \multicolumn{3}{|c|}{ Condition } \\
\hline & & & Identical & Variant & Unrelated \\
\hline \multirow[t]{2}{*}{ Subphonetic (VOT) } & Word & $\begin{array}{l}\text { Prime } \\
\text { Target }\end{array}$ & $\begin{array}{l}\text { peace } \\
\text { peace }\end{array}$ & $\begin{array}{l}p_{-2 / 3 \text { voт eace }} \\
\text { peace }\end{array}$ & $\begin{array}{l}\text { dog } \\
\text { peace }\end{array}$ \\
\hline & Nonword & $\begin{array}{l}\text { Prime } \\
\text { Target }\end{array}$ & /pif/ & $\begin{array}{l}/ \mathrm{p} /-2 / 3 \text { vor } / \text { if } / \\
/ \mathrm{pif} /\end{array}$ & $\begin{array}{l}\text { /gab/ } \\
\text { /pif/ }\end{array}$ \\
\hline \multirow[t]{2}{*}{ Syllable structure (Vowel deletion) } & Word & $\begin{array}{l}\text { Prime } \\
\text { Target }\end{array}$ & $\begin{array}{l}\text { police } \\
\text { police }\end{array}$ & $\begin{array}{l}\text { plice } \\
\text { police }\end{array}$ & $\begin{array}{l}\text { decide } \\
\text { police }\end{array}$ \\
\hline & Nonword & $\begin{array}{l}\text { Prime } \\
\text { Target }\end{array}$ & $\begin{array}{l}\text { /polif/ } \\
\text { /pəlif/ }\end{array}$ & $\begin{array}{l}\text { /plif/ } \\
\text { /palif/ }\end{array}$ & $\begin{array}{l}\text { /ravay // } \\
\text { /pəlif/ }\end{array}$ \\
\hline
\end{tabular}

consisting of $\mathrm{CVC}$ and multisyllabic nouns, verbs, or adjectives and their nonword counterparts. There were a total of 96 distractor items used in word-nonword and nonword-word pairs. These distractors were included so that the subjects could not predict from the presentation of the prime whether the target would be a word or a nonword. All multisyllabic distractors had unstressed first syllables and stressed second syllables. The two sets of distractors were matched for frequency, such that the CVC real-word list had the same number of high-, medium-, and low-frequency words as the multisyllable list. So that they more closely resembled the test items in phonological structure, one third of the distractor items in each list were / $\mathrm{p} /$-initial, one third were $/ \mathrm{k} /$-initial, and one third began with another consonant.

The stimuli were recorded by a 36-year-old phonetically trained male speaker of Canadian English who had lived in Providence, RI, for 4 years. The stimuli were presented to him for recording in orthographic form on $3 \times 5$ in. index cards and were blocked by item type (test item vs. distractor), word type (CVC vs. multisyllabic), and lexical status (word vs. nonword). In addition, a phonetic transcription of each nonword was provided below its orthographic form. The speaker was asked to read each block once silently before taping began and to read each item aloud four times before proceeding to the next item. For the multisyllabic blocks, the speaker was instructed to say each item four times in citation form, without reducing the initial syllable. Once the block was completed, he was asked to say each item again four times using a more informal speech style, thus producing a natural vowel deletion (e.g., police $\rightarrow$ / plis/). The utterances were recorded using a Nagra 4.5 reel-to-reel tape recorder with a Sony electret condenser microphone in a soundtreated room. Items were digitized onto a MicroVAX computer at a $20-\mathrm{kHz}$ sampling rate with a $9.0-\mathrm{kHz}$ low-pass filter and a 12-bit quantization. The four repetitions of each target were digitized using the Bliss waveform editor designed by John Mertus for the Brown University Speech Laboratory.

It was necessary to control the acoustic characteristics of the test stimuli as much as possible across conditions to reduce the likelihood of any existing systematic acoustic differences in the test stim- uli prior to introducing the VOT or vowel-deletion variation. For this reason, acoustic analysis was performed on all repetitions of both the CVC and the multisyllabic items, so that the most acoustically similar of the test items could be selected for use as targets. VOTs were measured by placing cursors at zero-crossings demarcating burst onset and the onset of phonation. In addition, the amplitude of the burst noise was measured in decibels for each target item at a bandwidth of $0-10 \mathrm{kHz}$ using a 15 -msec half-Hamming window placed at the onset of the burst. Selection of the particular target item from the four repetitions was based on its similarity to other targets in terms of both VOT and burst amplitude measures. Mean and standard deviation VOT and burst amplitude measures for stimuli across all conditions are shown in Table 2.

Subphonetic variant primes were created by excising the middle two thirds of the VOT for each CVC item, leaving intact the burst noise and the onset of phonation. Syllable structure variants were also created by a waveform editing process, to avoid a potential confound that could arise as a consequence of the editing of unsystematic variants. If subphonetic variants were created through a process of waveform editing and syllable structure variants were not, any difference in the pattern of results obtained across these variability types could be attributed to the editing of the stimuli and not to the source of variability itself. For this reason, syllable structure variant primes were created by splicing the onset of the reduced versions of the multisyllabic test targets onto the offset of the citation versions of the test targets (e.g., $\left.[\mathrm{pl}]_{\text {variant }}+[\mathrm{lis}]_{\text {citation }}\right)$. Onsets were defined as the portion of the waveform from the initial burst to the onset of phonation for the following sonorant, and offsets were defined as the portion of the waveform from the onset of phonation for the sonorant to word offset.

The completed stimulus set consisted of $96 \mathrm{CVC}$ (subphonetic) and multisyllabic (syllable structure) target words and nonwords, 96 corresponding phonologically/phonetically altered variant primes, 96 unrelated primes, and a set of 96 word and nonword distractors. These stimuli were transferred to an IBM-compatible computer for presentation to the participants. Target words and nonwords were paired in each of three conditions (see Table 1)-identity (prime

Table 2

Mean and Standard Deviation Voice-Onset Times (VOTs; in Milliseconds) and Burst Amplitudes (in Decibels) for All Modified Test Stimuli

\begin{tabular}{|c|c|c|c|c|c|c|c|c|c|}
\hline \multirow[b]{3}{*}{ Variability Type } & \multirow[b]{3}{*}{ Lexical Status } & \multicolumn{4}{|c|}{$/ \mathrm{p} /$} & \multicolumn{4}{|c|}{$/ \mathbf{k} /$} \\
\hline & & \multicolumn{2}{|c|}{ VOT } & \multicolumn{2}{|c|}{ Burst Amplitude } & \multicolumn{2}{|c|}{ VOT } & \multicolumn{2}{|c|}{ Burst Amplitude } \\
\hline & & $M$ & $S D$ & $M$ & $S D$ & $M$ & $S D$ & $M$ & $S D$ \\
\hline \multirow[t]{2}{*}{ Subphonetic (VOT) } & Word & 58.5 & 8.6 & 30.8 & 4.4 & 74.4 & 8.1 & 40.4 & 4.6 \\
\hline & Nonword & 60.3 & 6.1 & 30.9 & 5.1 & 77.2 & 8.5 & 40.7 & 4.4 \\
\hline \multirow[t]{2}{*}{ Syllable structure (Citation) } & Word & 59.3 & 8.2 & 29.1 & 3.8 & 71.2 & 7.0 & 34.1 & 3.2 \\
\hline & Nonword & 60.6 & 12.0 & 27.2 & 5.8 & 73.9 & 5.0 & 32.8 & 2.8 \\
\hline \multirow[t]{2}{*}{ Syllable structure (Vowel deletion) } & Word & 59.3 & 7.0 & 26.3 & 6.2 & 71.5 & 7.1 & 33.3 & 3.5 \\
\hline & Nonword & 59.8 & 11.1 & 29.9 & 7.4 & 72.6 & 6.1 & 31.9 & 4.6 \\
\hline
\end{tabular}


and target acoustically identical citation forms; e.g., peace-peace, police-police), variant (phonetically altered variant presented as prime, citation form presented as target; e.g., $p_{-2 / 3 \text { Vor }}$ eace-peace, [plis]-[palis]), and unrelated (unrelated word or nonword presented as prime, citation form presented as target; e.g., dog-peace, decide-police) -for a total of 288 test pairs. The test pairs were then randomly assigned to three lists of 96 pairs, such that no target item appeared more than once per list. Distractor words were paired with phonologically unrelated nonwords, and distractor nonwords were paired with phonologically unrelated words, for a total of 96 distractor pairs.

\section{Subjects}

Seventy students at Brown University, all monolingual native speakers of English, 18-25 years of age, were paid for their participation. Thirty students participated in the original identity priming experiment and the discrimination and identification posttests. An additional 30 students participated in the lexical decision posttest, and the remaining 10 participated in the word identification posttest. None of the subjects reported any history of hearing impairment, and all were naive to the purpose of the tasks.

\section{Procedure}

The subjects were seated in a sound-treated booth in front of a response box. Prior to each testing session, the subjects were instructed to respond to the stimuli as quickly and as accurately as possible, to use only the dominant hand, and to respond even if they were unsure of their answer. All stimuli were presented via Sony MDR-V2 headphones at a comfortable listening level.

The original 30 subjects received the identity priming task first, prior to any other perceptual task involving the test stimuli, to avoid effects of stimulus repetition on identity priming. Each subject received all of the priming conditions; however, as an additional control for repetition effects, each subject received only one occurrence of each test target. We accomplished this by assigning the subjects at random to one of the three lists of 96 test pairs. One third of the targets in each list was preceded by an identical prime, one third was preceded by a variant prime, and one third was preceded by an unrelated prime. Thus, each target item was heard in the identity condition by one subject, in the variant condition by another subject, and in the unrelated condition by a third subject.

The test pairs were presented in random order with a $50-\mathrm{msec}$ ISI and a 3,000-msec intertrial interval (ITI) and were preceded by a practice test consisting of 10 distractor pairs. The subjects were asked to indicate whether the second item in each pair was a word or a nonword by pressing one of two buttons marked "WORD" and "NONWORD."

To ensure that the subjects were perceptually sensitive to the acoustic manipulations performed on the prime words, four posttests were administered, including a discrimination task, a consonant identification task for the subphonetic stimuli, a lexical decision task for the multisyllabic stimuli, and a word identification task for the multisyllabic stimuli. The discrimination task was designed to test the subjects' ability to perceive the acoustic difference between the variant prime and the target across a $50-\mathrm{msec}$ ISI. The identification task was designed to ensure that the subjects identified the VOT-manipulated primes as voiceless in spite of the shortened VOT durations. The lexical decision posttest was included to ensure that the subjects maintained the same lexical decision judgments for the vowel-reduced stimuli as for the multisyllabic stimuli (i.e., [plis] vs. [palis]). The purpose of the word identification posttest was to ensure that the acoustic manipulations of the multisyllable word stimuli did not result in these stimuli being perceived as different words (e.g., police $\rightarrow$ please).

Stimuli for the discrimination posttest consisted of the 192 subphonetic and syllable structure test pairs for the identity and variant conditions. The subphonetic and syllable structure stimuli were presented in two separate tests, and the order of presentation of the two tests was counterbalanced across subjects. The test pairs were presented in random order with a $50-\mathrm{msec}$ ISI and a $3,000-\mathrm{msec}$ ITI. A practice test consisting of 12 pairs ( 6 same and 6 different) were presented prior to the beginning of each test series. The subjects were asked to indicate whether each pair sounded the same or different by pressing one of two response buttons marked "SAME" or "DIFFERENT."

For the consonant identification posttest, stimuli consisted of the subphonetic prime word stimuli including both the exemplar stimuli and the phonetically altered stimuli. A set of distractor stimuli that contained initial voiced stop consonants was also included. For these stimuli, the initial phoneme of the $\mathrm{CVC}$ word and nonword targets was changed from voiceless to voiced (e.g., peace $\rightarrow /$ bis/). These distractors were recorded and digitized in a manner identical to that used for the test items. Each of the distractor stimuli appeared twice. Stimuli for the identification task were presented to the subjects in random order with a 3,000-msec ITI. A practice test consisting of 16 items ( 4 test words, 4 variants, and 8 voiced distractors) was presented prior to the beginning of the test series. The subjects were asked to indicate whether each item began with the sound $/ \mathbf{p} /, / \mathbf{k} /, / \mathbf{b} /$, or $/ \mathrm{g} /$ by pressing one of two response buttons marked with the letters "p k" or "b g."

For the lexical decision posttest, stimuli consisted of the syllable structure prime stimuli including both the two-syllable exemplar stimuli and the vowel-reduced stimuli. The prime stimuli were divided into three lists (as was done for the identity priming experiment) such that no list contained more than one occurrence of each stimulus type. The 30 new subjects were assigned to one of the three lists. Stimuli for the lexical decision task were presented to the subjects in random order with a 3,000-msec ITI. A practice test consisting of 12 stimuli ( 6 words and 6 nonwords) was presented prior to the beginning of each test series. The subjects were asked to indicate whether the stimulus they heard was a word or not by pressing one of two response buttons marked "WORD" and "NONWORD."

The word identification posttest consisted of the altered and unaltered syllable structure prime stimuli, which were presented auditorily in random order to a new group of 10 subjects. The subjects were asked to write down whether each stimulus was a word or a nonword and, for word stimuli, to write down the word they heard.

The first 30 subjects received the identity priming task first, followed by the discrimination and consonant identification posttests. The order of presentation of the two posttests was counterbalanced across subjects. The subjects were tested in groups of 1-4 in three separate testing sessions over a period of 1-2 weeks. Of the remaining 40 subjects, 30 participated only in the lexical decision posttest for the syllable structure primes and 10 participated only in the word identification task for syllable structure primes.

Responses and RTs for all on-line tasks (identity priming, discrimination, identification, and lexical decision) were recorded by the IBM-compatible computer that controlled the experiment. RTs were measured from the onset of the second member of the pair for the identity priming task and the discrimination posttest and from the onset of the stimulus for the lexical decision posttest.

\section{RESULTS}

\section{Discrimination Posttest}

Mean and standard deviation RTs and error rates for subphonetic (VOT) and syllable structure (vowel-deletion) test pairs were determined in the discrimination task first, to establish whether the subjects were perceptually sensitive to the acoustic difference between intact and variant primes. RTs that were more than 2 standard deviations from the mean for each subject in each condition 
Table 3

Percentage of "SAME" and "DIFFERENT" Responses for the Discrimination Task

\begin{tabular}{lccrr}
\hline & & & \multicolumn{2}{c}{ Response } \\
\cline { 5 - 5 } \multicolumn{1}{c}{ Variability Type } & Lexical Status & Prime Condition & "SAME" & "DIFFERENT" \\
\hline Subphonetic (VOT) & Word & Identical & $\mathbf{8 8}$ & 7 \\
& & Variant & 48 & $\mathbf{4 8}$ \\
& Nonword & Identical & $\mathbf{8 7}$ & 9 \\
Syllable structure (Vowel deletion) & Word & Variant & 55 & $\mathbf{4 2}$ \\
& & Identical & $\mathbf{9 1}$ & 5 \\
& Nonword & Variant & 27 & $\mathbf{6 9}$ \\
& & Identical & $\mathbf{9 1}$ & 5 \\
& & Variant & 31 & $\mathbf{6 5}$ \\
\hline
\end{tabular}

Note-Correct responses are in bold. Owing to nonresponses and rejection of outliers, percentages within a condition may not sum to 100 .

were eliminated from the analysis. Percentages of "SAME" and "DIFFERENT" responses across conditions are shown in Table 3.

The subjects were expected to have difficulty discriminating the subphonetic (VOT) stimuli that differed in initial VOT, since the initial consonants in all pairs were supposed to be members of the same phonetic category. Thus, the subjects were being asked to detect within-category VOT differences. As Table 3 shows, the subjects were nevertheless able to detect such differences almost half of the time and were highly accurate at judging identical pairs. The subjects showed higher correct "DIFFERENT" discrimination scores for the syllable structure pairs, presumably because of the greater acoustic distance between the one-syllable variants and the corresponding intact two-syllable stimuli. On average, the subjects were able to discriminate these differences about two thirds of the time.

Three-way subject and item analyses of variance (ANOVAs) were performed for "SAME" responses, with variability type (VOT vs. vowel deletion), lexical status (word vs. nonword), and prime condition (identical vs. variant) as factors. All factors were treated as repeated measures in the subject analysis, whereas acoustic manipulation and lexical status were treated as betweensubjects factors in the item analysis. The analyses revealed a significant main effect of prime condition [subject, $F(1,29)=222.087, p<.0001$; item, $F(1,92)=442.743$, $p<.0001]$, such that there were more "SAME" responses to targets preceded by an identical stimulus than those preceded by a variant. This result suggests that the subjects were perceptually sensitive to the acoustic difference between intact stimuli and acoustic variants, in that the presence of an acoustic difference resulted in a reduction in the number of "SAME" responses. A significant main effect of variability type [subject, $F(1,29)=33.611, p<$ .0001 ; item, $F(1,92)=15.31, p<.001]$ was also obtained, such that there were significantly more "SAME" responses to subphonetic (VOT) pairs than to syllable structure (vowel-deletion) pairs. A significant main effect of lexical status emerged in the subject analysis $[F(1,29)=9.162$, $p<.01]$, such that there were more "SAME" responses to nonwords overall than to words. However, this effect did not approach significance in the item analysis $[F(1,92)=$ $0.899, p<.3]$.
In addition to these main effects, a significant variability type $\times$ prime condition interaction [subject, $F(1,29)=$ $58.869, p<.0001$; item, $F(1,92)=25.429, p<.0001]$ was obtained. Post hoc Newman-Keuls means comparisons revealed that, whereas the subjects made significantly more "SAME" responses to identical pairs than to acoustically different pairs across the two types of acoustic manipulations, they made significantly fewer "SAME" responses to syllable structure pairs than to subphonetic pairs when the target item was preceded by a variant. That is, the subjects were less likely to judge an acoustically different pair as identical in the syllable structure condition than in the subphonetic condition, suggesting that the subjects were more perceptually sensitive to the acoustic difference in the syllable structure condition. A significant lexical status $\times$ prime condition interaction emerged in the subject analysis $[F(1,29)=15.133, p<.001]$. Post hoc Newman-Keuls means comparisons showed that there were significantly fewer "SAME" responses to word stimuli than to nonword stimuli when the target item was preceded by a variant. Thus, the subjects were also less likely to judge an acoustically different pair as identical when the stimuli were words, rather than nonwords. However, this interaction was weak and failed to generalize across items $[F(1,92)=1.723, p>.1]$.

To further explore the perceptual effects of subphonetic and syllable structure acoustic variability, three-way repeated measures subject and item ANOVAs were performed on the RT data for "SAME" responses, with variability type (VOT vs. vowel deletion), lexical status (word vs. nonword), and prime condition (identical vs. variant) as factors. Two subjects gave no "SAME" responses to acoustically different syllable structure pairs, yielding no mean RT in this condition, and, therefore, their average RTs in the remaining experimental conditions could not be included in the repeated measures analysis. Table 4 shows mean (and standard deviation) RTs for "SAME" responses across conditions.

The raw RTs for each subject were log normalized prior to statistical analysis and averaged across conditions to reduce the amount of variability in the RT data. Significant main effects of prime condition [subject, $F(1,27)=$ $69.607, p<.0001 ;$ item, $F(1,90)=48.671, p<.0001]$, variability type [subject, $F(1,27)=70.813, p<.0001$; item, $F(1,90)=80.559, p<.0001]$, and lexical status 
Table 4

Mean and Standard Deviation Reaction Times (in Milliseconds) for "SAME" Responses in the Discrimination Task

Prime Condition

\begin{tabular}{llrrrrr} 
& & \multicolumn{3}{c}{ Prime Condition } \\
\cline { 3 - 4 } \cline { 6 - 7 } Variability Type & Lexical Status & $M$ & $S D$ & & \multicolumn{2}{c}{ Variant } \\
\cline { 3 - 4 } Subphonetic & Word & 944 & 272 & & 1,030 & 324 \\
& Nonword & 975 & 268 & & 1,029 & 275 \\
Syllable structure & Word & 1,073 & 300 & & 1,302 & 405 \\
& Nonword & 1,154 & 338 & & 1,432 & 388 \\
\hline
\end{tabular}

[subject, $F(1,27)=18.827, p<.001$; item, $F(1,90)=$ $5.691, p<.01]$ were obtained. The main effect of prime condition reflected significantly longer RTs obtained to items preceded by a variant than those obtained to items preceded by an identical stimulus. That is, the subjects' RTs for incorrect "SAME" judgments (i.e., "SAME" responses to pairs that were acoustically different) were significantly longer than for "SAME" responses to identical pairs, indicating that the subjects were sensitive to the acoustic difference between intact items and variants. The main effect of variability type was due to longer RTs overall to syllable structure (vowel-deletion) pairs than to subphonetic (VOT) pairs. This result is not surprising given that the syllable structure stimuli were longer in duration than the subphonetic stimuli and that RTs were measured from stimulus onset. The main effect of lexical status reflected longer RTs to nonword stimuli than to word stimuli-a finding that has been observed in a number of previous studies using a variety of experimental paradigms (e.g., Andruski et al., 1994).

In addition to the main effects, a significant interaction of variability type $\times$ prime condition [subject, $F(1,27)=$ $16.788, p<.001$; item, $F(1,90)=6.702, p<.01]$ was obtained. Post hoc Newman-Keuls means comparisons revealed that, while RTs were longer for pairs containing a variant than for identical pairs across variability types, this increase in RT to acoustically different pairs was greater for syllable structure than for subphonetic pairs. These results suggest that the subjects were more perceptually sensitive to the vowel-deletion manipulations than to VOT acoustic differences. The interaction of variability type $\times$ lexical status was significant in the subject analy$\operatorname{sis}[F(1,27)=10.068, p<.01]$. Post hoc Newman-Keuls analyses showed that the longer RTs obtained for nonword stimuli relative to word stimuli were significant only for syllable structure pairs. However, this interaction did not approach significance in the item analysis $[F(1,90)=$ $0.284, p>.5]$.

The results of the discrimination task demonstrate that the subjects were sensitive to the acoustic difference between intact stimuli and altered variants for both types of variability. The subjects produced significantly more "SAME" responses to pairs that were acoustically identical than to pairs containing a variant. Furthermore, the subjects demonstrated significantly longer RTs to acoustically different pairs that were judged to be the same than to acoustically identical pairs. These effects were obtained for both syllable structure and subphonetic variants, providing evidence that the subjects were perceptually sensitive to both types of variability.

The pattern of results obtained in the discrimination task also indicates that the subjects were more sensitive to the acoustic effects of syllable deletion than to effects of VOT reduction. They were significantly more likely to respond "SAME" to acoustically identical pairs in the syllable structure than in the subphonetic variability conditions. In addition, the subjects' RTs to incorrect "SAME" judgments (i.e., acoustically different pairs that were judged to be the same) were significantly longer in the syllable structure than in the subphonetic variability condition.

\section{Consonant Identification Posttest}

In order to establish whether the reduced VOTs of the CVC items were correctly perceived as voiceless stops, mean and standard deviation RTs and error rates for the identification task were determined. RTs that were more than 2 standard deviations from the mean for each subject in each condition were eliminated from the analysis.

While the two-thirds reduction in VOT was expected to result in both increased RTs and reduced overall accuracy in the identification task, it was necessary to determine whether this pattern of results was due to the general perceptual effect of the acoustic manipulations across all stimuli or to the misperception of a small set of specific stimuli. To address this question, the identification responses were examined across items prior to the statistical analysis, and those shortened VOT stimuli that failed to be identified correctly as voiceless by at least $66 \%$ of the subjects were eliminated from all subsequent analyses. Two nonword stimuli and one word stimulus were eliminated on this basis.

Percent correct and incorrect identification responses are shown in Table 5. The subjects were highly accurate at identifying unaltered VOTs as voiceless and were also quite accurate at identifying reduced VOTs as voiceless, although they identified a larger percentage of unaltered VOTs than altered VOTs as voiceless.

RT analyses of correct responses for the unaltered and altered stimuli are shown in Table 6. The raw RTs were log normalized prior to statistical analysis to reduce variability. Two-way subject and item ANOVAs were performed on the RT data, with phonetic parameter (identity vs. variant) and lexical status (word vs. nonword) as withinsubjects factors. Results revealed significant main effects of phonetic parameter [subject, $F(1,29)=48.049, p<$

Table 5

Percent Voiceless and Voiced Responses for the Identification Task Following Elimination of Poorly Identified Items

\begin{tabular}{lccccc}
\hline & \multicolumn{2}{c}{ Word } & & \multicolumn{2}{c}{ Nonword } \\
\cline { 2 - 3 } \cline { 5 - 6 } Stimulus & Voiceless & Voiced & & Voiceless & Voiced \\
\hline $\mathrm{p} / \mathrm{k}$ & 94 & 1 & 94 & 1 \\
$\mathrm{p} / \mathrm{k}_{-2 / 3 \text { VOT }}$ & 84 & 10 & & 86 & 10
\end{tabular}

Note-Owing to nonresponses and rejection of outliers, percentages within a condition may not sum to 100 . 
Table 6

Mean and Standard Deviation Response Times (in Milliseconds) for the Identification Task Following Elimination of Poorly Identified Items

\begin{tabular}{lccccc}
\hline & \multicolumn{2}{c}{ Word } & & \multicolumn{2}{c}{ Nonword } \\
\cline { 2 - 3 } \cline { 5 - 6 } Stimulus & $M$ & $S D$ & & $M$ & $S D$ \\
\hline $\mathbf{p} / \mathbf{k}$ & 797 & 117 & & 830 & 126 \\
$\mathrm{p} / \mathbf{k}_{-2 / 3 \text { VOT }}$ & 865 & 155 & & 923 & 182 \\
\hline
\end{tabular}

.0001 ; item, $F(1,43)=40.979, p<.0001]$ and lexical status [subject, $F(1,29)=30.008, p<.0001$; item, $F(1,43)=5.109, p<.05]$. That is, the subjects were significantly slower in identifying altered stimuli as voiceless than they were in identifying unaltered stimuli as voiceless, and they were significantly slower in responding to nonwords than to words. There was no significant interaction of phonetic parameter with lexical status. Thus, although the subjects identified the altered stimuli as voiceless, the two-thirds reduction in VOT was sufficient to slow RTs and reduce overall accuracy in the identification task. This pattern of results has been obtained in phonetic identification tasks in previous studies and has been taken as evidence that an acoustic manipulation produced a poorer exemplar of the intended phonetic category (Andruski et al., 1994; Utman, 1997, 1998a, 1998b; Utman et al., 1998). Thus, it appears that the VOT reduction in the present experiment resulted in poorer acoustic exemplars of the target items.

\section{Lexical Decision Posttest}

In order to establish that the acoustic manipulations of the multisyllable stimuli did not affect the lexical status of the primes, mean and standard deviation RTs and error rates for the lexical decision judgments of the syllable structure prime stimuli were determined. RTs that were more than 2 standard deviations from the mean for each subject in each condition were eliminated from the analysis. Because of a technical problem, the data for 1 subject was not usable. Thus, the analyses below are based on a total of 29 subjects.

Percent correct identification responses are shown in Table 7. Results show that the subjects did very well at making correct lexical decision judgments for the prime stimuli, although they made more errors on the vowelreduced real-word stimuli (i.e., police $\rightarrow$ [plis]). Nonetheless, a two-way subject and item analysis of variance, with phonetic parameter (unaltered vs. altered) and lexical status (word vs. nonword) as within-subjects factors, revealed significant main effects for phonetic variant [subject, $F(1,28)=8.218, p<.0078$; item, $F(1,23)=$ $6.364, p<.019$ ] and lexical status [subject, $F(1,28)=$ $14.005, p<.0008$; item, $F(1,23)=4.847, p<.038]$, but no variant $\times$ lexical status interaction [subject, $F(1,28)=$ 1.876; item, $F(1,23)=2.237$ ]. Thus, lexical decisions were less accurate for altered stimuli than for unaltered stimuli and less accurate for word stimuli than for nonword stimuli. However, the lexical decisions for altered word primes were not significantly worse than those for altered nonwords.

On the basis of the lexical decision performance on the multisyllabic prime stimuli, those stimuli for which $66 \%$ of the subjects failed to make correct lexical decision judgments were eliminated from the data analysis in the identity priming task. Four word stimuli and one nonword stimulus were eliminated on this basis.

RT analyses of correct lexical decision judgments are shown in Table 8. The raw RT data were log normalized prior to statistical analyses to reduce variability. Two-way subject and item ANOVAs were performed on the RT data, with phonetic parameter (identity vs. variant) and lexical status (word vs. nonword) as within-subjects factors. Results revealed a marginally significant effect of phonetic parameter by subject $[F(1,28)=3.267, p<$ $.0815]$ but not by item $[F(1,23)=1.364]$, a significant effect of lexical status [subject, $F(1,28)=23.8, p<.0001$; item, $F(1,23)=6.114, p<.0212$ ], and a significant phonetic variant $\times$ lexical status interaction [subject, $F(1,28)=$ $23.355, p<.0001$; item, $F(1,23)=9.321, p<.0056]$. That is, the subjects showed overall slower lexical decision latencies for nonwords than for words. However, the effect emerged only in the unaltered condition. In addition, consistent with the accuracy data, RTs were slower for altered words than for unaltered words. Thus, the RT data revealed that the acoustic manipulations slowed responses to the word stimuli, but similar effects failed to emerge for the nonword stimuli.

\section{Word Identification Posttest}

The subjects' written lexical decision judgments to syllable structure prime stimuli were scored for accuracy, as were the written identification responses to word stimuli. As in the lexical decision posttest, the subjects were quite accurate in distinguishing words from nonwords, whether or not the stimuli were acoustically altered. The identification results for each word stimulus are shown in Appendix B. A paired $t$ test revealed no significant difference in identification performance between altered and unaltered stimuli $[t(1,20)=1.82]$. Taken together, the results of the word identification and lexical decision posttests indicate that the acoustic manipulations did not significantly affect the identification or lexical status of the altered multisyllable primes.

\section{Identity Priming Task}

The data from the identity priming experiment were scored for both accuracy and RT. RTs that were more than

Table 7

Percent Correct Lexical Decision Judgments of the Syllable Structure Prime Stimuli

\begin{tabular}{ccc}
\hline Stimulus & Word & Nonword \\
\hline $\begin{array}{c}\text { Citation form } \\
\text { (Unaltered) } \\
\text { Variant } \\
\text { (Vowel deletion) }\end{array}$ & 91 & 95 \\
\hline
\end{tabular}


Table 8

Mean and Standard Deviation Response Times (in Milliseconds) for Correct Lexical Decision Judgments for the Syllable Structure Prime Stimuli

\begin{tabular}{cccccc}
\hline & \multicolumn{2}{c}{ Word } & & \multicolumn{2}{c}{ Nonword } \\
\cline { 2 - 3 } \cline { 5 - 6 } Stimulus & $M$ & $S D$ & & $M$ & $S D$ \\
\hline $\begin{array}{c}\text { Citation form } \\
\quad \text { (Unaltered) }\end{array}$ & 1,114 & 204 & & 1,295 & 249 \\
$\begin{array}{l}\text { Variant } \\
\text { (Vowel deletion) }\end{array}$ & 1,217 & 213 & & 1,252 & 232 \\
\hline
\end{tabular}

2 standard deviations from the mean for each subject in each condition were eliminated from the analysis. Subphonetic items that failed to be identified as voiceless by $66 \%$ of the subjects in the consonant identification posttest and multisyllable items that failed to be judged as the correct lexical decision by $66 \%$ of the subjects in the lexical decision posttest were eliminated from the analysis (see above), including the altered test pairs and the corresponding identical and unrelated test pairs. Mean correct and incorrect lexical decision judgments in the identity priming task are shown in Table 9. As the table indicates, the subjects were highly accurate at judging the lexical status of the target item across priming conditions. Mean and standard deviation RTs are shown in Table 10.

Raw RTs were log normalized prior to statistical analysis to reduce variability. Subject and item variability type (subphonetic vs. syllable structure) $\times$ lexical status (word vs. nonword) $\times$ prime condition (identity vs. variant vs. unrelated) ANOVAs were performed on the RT data, assuming repeated measures for all factors in the subject analysis and treating variability type as a betweensubjects factor in the item analysis. Results revealed significant main effects of variability type [subject, $F(1,29)=$ $247.879, p<.0001$; item, $F(1,84)=85.566, p<.0001]$, lexical status [subject, $F(1,29)=27.454, p<.0001$; item, $F(1,84)=23.869, p<.0001]$, and prime condition [subject, $F(2,58)=97.207, p<.0001$; item, $F(2,168)=$ $61.515, p<.0001]$. The main effect of variability type reflected significantly longer RTs to targets in the syllable structure (vowel-deletion) condition than in the subphonetic (VOT) condition, which may be attributed to the difference in the durations of the targets themselves, since multisyllabic targets were longer in duration than single syllable targets. The main effect of lexical status was due to longer RTs to nonwords than to words, irrespective of prime condition or variability type. Post hoc NewmanKeuls means comparisons of the main effect of prime condition revealed significant identity priming (i.e., speeded RTs relative to targets preceded by a phonologically unrelated prime) for targets preceded by both identical primes and variants.

In addition to the main effects, there was also a significant variability type $\times$ prime condition $\times$ lexical status interaction [subject, $F(2,58)=10.992, p<.0001$; item, $F(2,168)=6.046, p<.01]$, indicating that the effects of different types of variability on identity priming differed significantly according to the lexical status of the target item. This result was examined further in separate ANOVAs for "WORD" and "NONWORD" responses, with variability type (subphonetic vs. syllable structure) as a within-subjects factor in the subject analyses and as a between-subjects factor in the item analyses and with prime condition (identity vs. variant vs. unrelated) as a within-subjects factor in both the subject analysis and the item analysis.

The analysis of RTs to word stimuli ("WORD" responses) revealed significant main effects of both variability type [subject, $F(1,29)=180.593, p<.0001$; item, $F(1,41)=57.478, p<.0001]$ and prime condition [subject, $F(2,58)=104.363, p<.0001$; item, $F(2,82)=$ $36.442, p<.0001]$. As in the three-factor ANOVA, the main effect of variability type was due to longer RTs to targets in the syllable structure (vowel-deletion) condition than in the subphonetic (VOT) condition. Post hoc Newman-Keuls means comparisons for the main effect of prime condition showed significant identity priming for both identical stimuli and variants across both sources of variability.

In addition to these main effects, there was a significant variability type $\times$ prime condition interaction [subject, $F(2,58)=4.797, p<.0001$; item, $F(2,82)=3.968, p<$ $.05]$, owing to different patterns of performance in the subphonetic and the syllable structure variability conditions. Post hoc Newman-Keuls means comparisons revealed that, in the subphonetic variability condition, the subjects were significantly slower in responding to targets preceded by a variant prime than in responding to targets preceded by an identical prime. That is, the subphonetic VOT reduction in the word primes significantly reduced the amount of identity priming obtained for a target. In the syllable structure variability condition, however, the subjects were significantly faster in responding to targets preceded by a variant prime than in responding to targets preceded by an identical prime. The variants generated by a vowel deletion in the multisyllabic word primes thus produced more priming than an identical prime word.

The analysis of RTs to nonword stimuli ("NONWORD" responses) revealed significant main effects of variability type [subject, $F(1,29)=134.926, p<.0001$; item, $F(1,43)=33.534, p<.0001]$ and prime condition [subject, $F(2,58)=39.074, p<.0001$; item, $F(2,86)=26.219$, $p<.0001]$. As in the analysis of word stimuli, the main effect of variability type was due to longer RTs to targets in the syllable structure condition than in the subphonetic

Table 9

Percent Correct Lexical Decision Judgments by Prime Type for the Identity Priming Task

\begin{tabular}{llccc}
\hline & & \multicolumn{3}{c}{ Prime Type } \\
\cline { 3 - 5 } Variability Type & Lexical Status & Identical & Variant & Unrelated \\
\hline Subphonetic & Word & 93 & 93 & 93 \\
\multirow{3}{*}{ Syllable structure } & Nonword & 91 & 92 & 92 \\
& Word & 92 & 93 & 93 \\
& Nonword & 90 & 92 & 92 \\
\hline
\end{tabular}


Table 10

Mean and Standard Deviation Response Times (in Milliseconds) by Prime Type for the Identity Priming Task

\begin{tabular}{|c|c|c|c|c|c|c|c|}
\hline \multirow[b]{3}{*}{ Variability Type } & \multirow[b]{3}{*}{ Lexical Status } & \multicolumn{6}{|c|}{ Prime Type } \\
\hline & & \multicolumn{2}{|c|}{ Identical } & \multicolumn{2}{|c|}{ Variant } & \multicolumn{2}{|c|}{ Unrelated } \\
\hline & & $M$ & $S D$ & $M$ & $S D$ & $M$ & $S D$ \\
\hline \multirow[t]{2}{*}{ Subphonetic } & Word & 804 & 248 & 834 & 215 & 949 & 188 \\
\hline & Nonword & 945 & 290 & 889 & 247 & 1,058 & 248 \\
\hline \multirow[t]{2}{*}{ Syllable structure } & Word & 1,008 & 233 & 957 & 244 & 1,154 & 306 \\
\hline & Nonword & 1,046 & 259 & 1,124 & 340 & 1,230 & 268 \\
\hline
\end{tabular}

condition. Similar to the findings of the analysis of word stimuli, post hoc Newman-Keuls means comparisons of the main effect of prime condition showed significant identity priming for both identical stimuli and variants across both sources of variability. The variability type $x$ prime condition interaction was highly significant in the subject analysis $[F(2,58)=5.335, p<.01]$ but failed to generalize across items $[F(2,86)=2.288, p>.1]$. Post hoc Newman-Keuls means comparisons performed on the data from the subject analysis revealed the reverse pattern of results to that observed in the analysis of word stimuli: In the subphonetic variability condition, significantly more priming was observed for variant primes than for identical primes, whereas in the syllable structure variability condition, variant primes produced significantly less priming than identical primes. In other words, for nonword stimuli, the subphonetic VOT reduction increased identity priming, whereas the syllable structure vowel deletion significantly reduced priming. However, these results should be interpreted with caution, since they reflect RTs to "NONWORD" (i.e., "no") responses in the lexical decision task, and the observed effects failed to generalize across stimulus items.

In summary, the results of the lexical decision task suggest that subphonetic variability and syllable structure variability have different effects on priming. Interestingly, these effects appear to be influenced by the lexical status of the target item: Variant primes produced by subphonetic variation reduce priming to word targets, but not to nonword targets, whereas variant primes produced by syllable structure variation reduce priming to nonword targets, but not to word targets.

\section{DISCUSSION}

The results of this study indicate that natural acoustic variations as exemplified by either changes in the VOT value of initial voiceless stop consonants or vowel deletion in initial unstressed syllables in multisyllable words affect word recognition processes. Although significant identity priming occurred with both types of variations, the magnitude of priming differed significantly from that obtained for stimulus primes that were acoustically identical to the targets. Of particular importance was the significant variability type $\times$ prime condition $\times$ lexical status interaction, which indicated that the overall pattern of priming results differed not only as a function of the type of acoustic variation but also as a function of the lexical status of the stimuli.

Subphonetic variation (VOT reduction) resulted in reduced priming effects for words when the prime was acoustically manipulated relative to when the prime was acoustically identical to the target. In contrast, nonwords failed to show reduced priming effects for acoustically manipulated primes. Results for syllable structure variation (vowel deletion) showed the opposite pattern. Syllable structure variants showed significantly increased identity priming relative to acoustically identical prime target pairs for words and showed significantly reduced identity priming effects for nonwords. Thus, subphonetic variations slowed responses to words but not to nonwords, whereas syllable structure variations slowed responses to nonwords and speeded responses to words.

The results obtained for word stimuli lend further evidence in support of the view that lexical activation is graded (Andruski et al., 1994) and that the extent of lexical activation is a function of the relationship between the acoustic input and the corresponding lexical representation. Subphonetic (unsystematic) manipulations affect the "goodness" of the phonetic category and produce a degraded version of the representation of the lexical entry (cf. Andruski et al., 1994; Utman, 1998a). Although the acoustically altered stimulus was identified as voiceless by the subjects, it was acoustically closer to the voiced phonetic category. VOT values of a voiceless stop consonant that are shorter and closer to the voiced phonetic category are perceived as poorer exemplars of the voiceless phonetic category (Andruski et al., 1994; Utman, 1998a; cf. Volaitis \& Miller, 1992). At the extreme, short VOT values are perceived as a different phonetic category - namely, voiced. In contrast, syllable structure variants are true alternate variants and, in this sense, are not degraded. Unlike the subphonetic variants, both of the syllable structure variants in the present experiment are associated with the same lexical entry and are "good" exemplars of that entry. Furthermore, unlike subphonetic variation, there are language-particular phonological rules that allow for syllable structure variation. The results of the present study suggest that the processes of formbased word recognition treat subphonetic (within-category) variations differently from phonological (syllable-based) variations.

The results clearly indicate that it is not necessarily the acoustic distance between prime and target that determines 
the magnitude of identity priming for words. The syllable structure variant primes were acoustically more distant from the unaltered targets than were the subphonetic variants. Thus, if acoustic distance alone determined the magnitude of identity priming, vowel-deleted primes should have shown reduced priming or no priming relative to the acoustically identical syllable structure prime stimuli, and the magnitude of priming for subphonetic variations should have been greater than those for syllable structure variants. The results showed, in fact, greater priming for syllable structure variants relative to acoustically identical stimuli and a greater magnitude of priming for syllable structure variants relative to subphonetic variants. Moreover, the greater priming for the vowel-deleted stimuli emerged despite the fact that these variants were perceptually more distinct from the unmanipulated stimuli than were the subphonetic variants, as shown by the subjects' performance in a discrimination task. This increase in priming may reflect the frequency with which the voweldeleted stimuli are encountered in natural speech, since it is probably the case that speakers are more likely to use a casual speaking style. If the formation of category structure relates to the nature of the input exemplars, as has been suggested in studies of category formation in vision (cf. Posner \& Keele, 1968; Knapp \& Anderson, 1984), then greater priming should occur as the stimulus input matches the more common phonetic manifestation.

The question remains how current models of word recognition can account for the present findings, particularly for the increased identity priming effects for syllable structure variants. The issue centers around what the nature of the lexical representation is for such stimuli and how different exemplars map onto that representation. The standard view is that there is a single word form representation for each lexical entry. The better the match between the acoustic input and the lexical representation, the greater the amount of identity priming. Different acoustic variants may represent different acoustic and perceptual consequences of continuous variation occurring in natural speech (Browman \& Goldstein, 1990). Both phonological and subphonetic variants may therefore be treated similarly under this approach, with more frequently encountered variants representing better exemplars, and thus producing more lexical activation, than less frequent variants. Alternatively, different variants may reflect segmental, categorical, rule-governed phonological processes of a language that may allow for segment deletion under certain phonetic conditions (Lahiri \& Marslen-Wilson, 1991). In the cohort model, for example, lexical representations are highly abstract, incorporating the properties of underspecification and markedness that have emerged from linguistic theories of autosegmental phonology (cf. Lahiri \& Marslen-Wilson, 1991). Thus, each representation contains only sufficient featural information to distinguish it from other candidates, and incoming featural information can be incompatible only with information that is directly specified in the lexical representation and not with unspecified featural information. This means that lexical rep- resentations may be underspecified for variations that result from the operation of phonological rules on surface forms. In this way, phonological variants will not result in incompatibility of the acoustic input with the underlying form.

Another possibility is that there may be several entries for a word, and these entries may map onto the same lexical candidate. These distinct variants may be lexically coded, with the choice of variant determined probabilistically as a function of speaking style and local environment (Browman \& Goldstein, 1990). Alternatively, such variants may reflect categorical rule-governed representations. For example, in Klatt's (1979) LAFS system, rulegoverned variability is precompiled in the network, such that more than one pathway can converge on a single word unit, allowing for a word and its derived phonological variants to map directly onto the same word.

While the findings of the present study cannot distinguish among these various possibilities, the data suggest that if there is a single lexical representation for syllable structure variants, the form of that lexical representation appears to reflect the more frequent phonetic manifestation-namely, the vowel-reduced stimulus. The influence of the frequency of acoustic variants on word recognition is consistent with an account of lexical access in which both subphonetic and syllable structure variation are continuous, with some variants representing better exemplars of a lexical representation than others. Single lexical representations are graded under this approach, such that bottom-up activation levels reflect this structure (cf. Andruski et al., 1994; Utman, 1998b; Utman et al., 1998). Such an account assumes that lexical representations are formed through repeated exposure to multiple acoustic exemplars, similar to the process proposed for visual category formation (Knapp \& Anderson, 1984; Posner \& Keele, 1968). Thus, more frequently perceived exemplars are more strongly associated with the corresponding lexical entry, producing more lexical activation than less frequent exemplars.

The data from the present study may present a challenge to the cohort model's characterization of rule-governed variability. Specifically, it is not clear whether the hypothesized underspecified representations can account for how the listener maps phonological variants with a different syllable structure onto the same representation. Lahiri and Marslen-Wilson (1991) do not address the question of how underspecified representations can accommodate rules of deletion and resyllabification, such as /polis/ $\rightarrow$ /plis/, which serve to remove an element from the segmental tier of an autosegmental representation. The issue of recoverability of deleted segments is not a trivial one and has been the focus of much discussion in linguistic theory (cf. Lass, 1984). In particular, while it is straightforward to apply phonological rules to generate a reduced surface form given a fully specified representation or underlying form (e.g., /palis / $\rightarrow$ /plis /), it is not obvious how to accomplish the reverse-that is, to derive from a syllabically reduced surface form such as 
/plis / the fully specified representation / palis/. The difficulty arises because there are other surface forms, such as / plæn / (i.e., plan), that do not undergo syllable reduction, and, hence, such words map transparently onto a fully specified underlying representation. Underspecified representations, such as those proposed in recent versions of cohort theory (Lahiri \& Marslen-Wilson, 1991), can accommodate variants produced by phonological rules that affect the phonetic realization of a lexical item at the featural level (e.g., the assimilation of place of articulation, as in sweet girl $\rightarrow$ /swik grl/; Marslen-Wilson, 1993). However, it has not yet been demonstrated how two variants that differ in syllabic structure could successfully map onto a single representation, however underspecified. Similar problems arise for any model of word recognition or lexical processing that posits a single representation to accommodate all phonological variants. In contrast, models in which phonological variants map directly onto the same lexical entry, such that rule-governed variability is precompiled as in the LAFS model (Klatt, 1979), can account for variation in both phonetic features and syllable structure.

Interestingly, the pattern of results obtained for nonwords in the present experiment differed substantially from that obtained for words in response to both subphonetic and syllable structure variation. The results for subphonetic variation are consistent with earlier findings (Marslen-Wilson \& Warren, 1994; Streeter \& Nigro, $1979)$ that showed similar interaction effects between subphonetic variability and lexical status. The results of the present study showing greater priming for nonwords in the variant condition than in the identity condition are difficult to interpret and should be taken with caution, given that the interaction of variability type $\times$ prime condition for the nonword data were significant only by subject and not by item. Nonetheless, the present findings are similar to other results in the literature showing a failure of subphonetic acoustic manipulations to slow RTs to nonwords, as they do to words (Marslen-Wilson \& Warren, 1994; Streeter \& Nigro, 1979). Several interpretations have been put forth for these findings. One possibility is that nonwords do not show effects of phonetic degradation because of a failure to find a lexical match (Streeter \& Nigro, 1979). This interpretation is similar to the proposal, discussed in the introduction, that nonwords are not exemplars of a particular lexical entry and therefore do not produce a graded response for within-category acoustic variations. Thus, rather than reflecting the degree to which the acoustic input matches an existing lexical entry, the lexical decision response reflects the absence of a lexical match. Furthermore, because there is total phonemic overlap between the prime and the target, the acoustic difference between the stimuli is not in itself sufficient to reduce the magnitude of identity priming. Another possibility is that nonwords are processed by analogy to words, and the failure to show the influence of acoustic manipulations on nonwords reflects a failure to find a stable attractor state (Marslen-Wilson \& Warren, 1994).
The finding that the syllable structure variants affected the amount of priming obtained for nonwords allows for two alternative interpretations. The first raises the possibility that nonwords may not always be processed by analogy to real words as suggested by Marslen-Wilson and Warren (1994; cf. Whalen, 1991). If nonwords were processed by analogy to real words, similar findings should have emerged for the multisyllable variants as for the unsystematic variants. Namely, the acoustic manipulations should have failed to reduce the priming effects for nonword targets when preceded by phonological variants. The acoustic manipulations on nonwords did reduce the amount of priming, however, even though the acoustic manipulations were the same for both word and nonword stimuli and the nonword stimuli were identical to the word stimuli except for the final segment. These findings suggest that, at least under some conditions, acoustic differences in nonwords may be processed with respect to the differences among the physical characteristics of the stimuli without reference to the lexicon.

An alternative interpretation of the findings for syllable structure variation in nonwords is consistent with Marslen-Wilson and Warren's (1994) proposal that nonwords are processed by analogy to real words. If nonwords are treated as potential lexical candidates, the phonologically manipulated prime stimuli would activate a different set of lexical candidates from the fully specified target. That is, the acoustically manipulated prime (e.g., [plif]) would activate the cohort of words with the phonetic structure \#plVC\# (e.g., plan) and perhaps also \#pəlVC\# (e.g., police), whereas the target stimulus would activate only the cohort of words with the structure \#polVC\# (e.g., police). Partial activation of multiple representations could reduce the amount of priming for nonwords in the syllable structure variant condition.

In summary, the results of this study show that both subphonetic variability and syllable structure variability have effects on word recognition. Importantly, these effects differ depending on the type of variability in question and also depending on lexical status. Subphonetic variation, which affects within-category acoustic information associated with phonetic segments, reduced identity priming in the present study for words but not for nonwords. In contrast, syllable structure variation, which affects the phonological structure of the acoustic input, increased priming for words and decreased priming for nonwords. These results suggest that the two types of variation are treated differently by the word recognition system. Nevertheless, the two patterns can be accommodated under an account of lexical access that assumes that both types of variation produce a continuous series of acoustic variants that represent better or poorer exemplars of the intended lexical entry and that the graded nature of lexical representations reflects this continuum.

\section{REFERENCES}

Andruski, J. E., Blumstein, S. E., \& Burton, M. W. (1994). The effect of subphonetic differences on lexical access. Cognition, 52, 163-187. Browman, C. P., \& GoldSTEIN, L. (1990). Gestural specification using 
dynamically-defined articulatory structures. Journal of Phonetics, 18, 299-320.

Burton, M. W. (1989). Associated, mediated, and rhyme priming: $A$ study of lexical processing. Unpublished doctoral dissertation, Brown University. .

Church, K. W. (1987). Phonological parsing and lexical retrieval. Cognition, 25, 53-69.

Dalby, J. (1985). Phonetic structure of fast speech in American English. Unpublished doctoral dissertation, Indiana University.

FRANCIS, W. N., \& KuČERA, H. (1982). Frequency analysis of English usage: Lexicon and grammar. Boston: Houghton Mifflin.

Frauenfelder, U., \& Lahiri, A. (1989). Understanding words and word recognition. In W. D. Marslen-Wilson (Ed.), Lexical representation and process (pp. 319-341). Cambridge, MA: MIT Press.

FraZIER, L. (1987). Structure in auditory word recognition. Cognition, 25, 157-187.

Gaskell, M. G., \& Marslen-Wilson, W. D. (1996). Phonological variation and inference in lexical access. Journal of Experimental Psychology: Human Perception \& Performance, 22, 144-158.

Kessinger, R. H., \& Blumstein, S. E. (1997). Effects of speaking rate on voice-onset time in Thai, French, and English. Journal of Phonetics, 25, 143-168.

KLATT, D. H. (1975). Voice onset time, friction, and aspiration in wordinitial consonant clusters. Journal of Speech \& Hearing Research, 18, 686-706.

KLATT, D. H. (1979). Speech perception: A model of acoustic-phonetic analysis and lexical access. Journal of Phonetics, 7, 279-312.

KLATT, D. H. (1986). The problem of variability in speech recognition and in models of speech perception. In J. Perkell \& D. H. Klatt (Eds.), Invariance and variability in speech processes. Hillsdale, NJ: Erlbaum.

KNAPP, A. G., \& ANDERson, J. A. (1984). Theory of categorization based on distributed memory storage. Journal of Experimental Psychology: Learning, Memory, \& Cognition, 10, 616-637.

LAhIRI, A., \& Marslen-Wilson, W. D. (1991). The mental representation of lexical form: A phonological approach to the recognition lexicon. Cognition, 38, 245-294.

Lass, R. (1984). Phonology: An introduction to basic concepts. Cambridge: Cambridge University Press.
MarSLEN-Wilson, W. D. (1993). Issues of process and representation in lexical access. In G. T. M. Altmann \& R. Shillcock (Eds.), Cognitive models of language processes: The Second Sperlonga Meeting (pp. 187-210). Hove, U.K.: Erlbaum.

Marslen-Wilson, W. D., Moss, H. E., \& van Halen, S. (1996). Perceptual distance and competition in lexical access. Journal of Experimental Psychology: Human Perception \& Performance, 22, 1376-1392.

MARSLEN-WiLson, W. D., \& WARREN, P. (1994). Levels of perceptual representation and process in lexical access: Words, phonemes, and features. Psychological Review, 101, 653-675.

Miller, J. L., Green, K., \& ReEves, A. (1986). Speaking rate and segments: A look at the relation between speech production and speech perception for the voicing contrast. Phonetica, 43, 106-115.

Posner, M. I., \& KeEle, S. W. (1968). On the genesis of abstract ideas. Journal of Experimental Psychology, 77, 353-363.

SlowiaczeK, L. M., \& Pisoni, D. B. (1986). Effects of phonological similarity on priming in auditory lexical decision. Memory \& Cognition, 14, 230-237.

Streeter, L. A., \& Nigro, G. N. (1979). The role of medial consonant transitions in word perception. Journal of the Acoustical Society of America, 65, 1533-1541.

UTMAN, J. A. (1997). Effects of subphonetic acoustic differences on lexical access in neurologically intact adults and patients with Broca's aphasia. Unpublished doctoral dissertation, Brown University.

UTMAN, J. A. (1998a). Effects of local speaking rate context on the perception of voice-onset time in initial stop consonants. Journal of the Acoustical Society of America, 103, 1640-1653.

UTMAN, J. A. (1998b). The role of phonetic exemplars in the mapping from sound to meaning. Manuscript submitted for publication.

Utman, J. A., Blumstein, S. E., \& Sullivan, K. (1998, April). Mapping from sound to meaning: Reduced lexical activation in Broca's aphasics. Paper presented at the annual meeting of the Cognitive Neuroscience Society, San Francisco.

Volaitis, L., \& Miller, J. L. (1992). Phonetic prototypes: Influence of place of articulation and speaking rate on the internal structure of phonetic categories. Journal of the Acoustical Society of America, 92, 723-735.

WHALEN, D. H. (1991). Subcategorical phonetic mismatches and lexical access. Perception \& Psychophysics, 50, 351-360. 
APPENDIX A

Stimuli

\begin{tabular}{cl}
\hline Subphonetic & Syllable Structure \\
\hline poke & parade \\
pose & parole \\
pool & peruse \\
peak & parental \\
pen & palatial \\
peace & police \\
pack & parameter \\
pot & polemic \\
pat & political \\
pace & perennial \\
put & polite \\
pain & paralysis \\
keep & career \\
kiss & caress \\
can & collide \\
cane & careen \\
cause & collect \\
cuff & collegiate \\
cut & corrosive \\
care & collective \\
cat & collusion \\
case & colonial \\
code & collaborate \\
cut & corroborate \\
\hline
\end{tabular}

APPENDIX B

Word Identification Results (Number Correct)

for Multisyllable Word Stimuli $(N=10)$

\begin{tabular}{lrr}
\hline \multicolumn{1}{c}{ Stimulus } & Citation Form & Variant \\
\hline careen & 7 & 5 \\
career & 10 & 10 \\
caress & 10 & 9 \\
collaborate & 10 & 9 \\
collect & 10 & 6 \\
collective & 10 & 10 \\
collegial & 9 & 7 \\
collusion & 3 & 8 \\
colonial & 9 & 9 \\
corroborate & 8 & 7 \\
corrosion & 8 & 8 \\
palatial & 5 & 7 \\
paralysis & 10 & 9 \\
parameter & 9 & 10 \\
parental & 10 & 8 \\
parole & 9 & 8 \\
perennial & 9 & 6 \\
peruse & 10 & 8 \\
polemic & 9 & 5 \\
police & 10 & 8 \\
political & 9 & 10 \\
\hline
\end{tabular}

